\title{
Correction to: Estimating capital requirements to scale health microinsurance serving rural poor populations
}

\author{
David M. Dror ${ }^{1} \cdot$ Atanu Majumdar ${ }^{2} \cdot$ Nihar Jangle $^{3}$
}

Published online: 30 April 2019

(C) The Geneva Association 2019

\section{Correction to: The Geneva Papers on Risk and Insurance - Issues and Practice (2019) https://doi.org/10.1057/s41288-019-00126-w}

In the first published version of this article the abstract contained an error. The sentence 'Probability of bankruptcy is fixed at 99.9\%.' was replaced with the sentence 'Capital requirements drop significantly when confidence levels are lower than 99.9.' The original article has been corrected.

Publisher's Note Springer Nature remains neutral with regard to jurisdictional claims in publishedmaps and institutional affiliations.

The original article can be found online at https://doi.org/10.1057/s41288-019-00126-w.

Atanu Majumdar

atanu@mia.org.in

David M. Dror

daviddror@socialre.org

Nihar Jangle

nihar.jangle@gmail.com

1 Social Re Consultancy Pvt. Ltd, New Delhi, India

2 Social Re Consultancy Pvt. Ltd./Micro Insurance Academy, A-157, Ground Floor, DDA Double Storey Flats, Garhi, East of Kailash, New Delhi 110065, India

3 Deutsche Gesellschaft für Internationale Zusammenarbeit (GIZ) GmbH, Bonn, Germany 